\title{
Dynamic Behaviour of Air Valves in a Large-Scale Pipeline Apparatus
}

\author{
Anton Bergant 1 ,* - Arno Kruisbrink ${ }^{2}$ - Francisco Arregui ${ }^{3}$ \\ ${ }^{1}$ Litostroj Power d.o.o., Slovenia \\ 2 University of Nottingham, United Kingdom \\ 3 Universidad Politecnica de Valencia, Spain
}

\begin{abstract}
This paper describes an experimental programme on the dynamic behaviour of air valves performed in a large-scale pipeline apparatus. Dynamic flow tests were performed at large (full) scale, since previous quasi-steady flow tests at small scale did not lead to realistic results. Investigations in a large-scale pipeline apparatus lead to a better understanding of the physical processes associated with the dynamic performance of air valves. Float type air valves of nominal diameter of 50 and $100 \mathrm{~mm}$ were tested in geometrically similar $200 \mathrm{and} 500 \mathrm{~mm}$ test sections, to allow for the assessment of dynamic scale effects and the development of dimensionless parameter groups and dynamic scale laws. The approach in the determination of the dynamic performance of air valves was to measure their response to flow acceleration/ decelerations, which are imposed upon the valve. In this way, the air valve behaviour following events like system start-up, pump trip and pipe rupture is simulated. Key results of the dynamic flow tests, including air release tests (valve slam) and column separation tests (effect of air valve on surge suppression), are presented and discussed.
\end{abstract}

Keywords: air valves, large-scale test facility, dynamic flow test, air admission, air release, water hammer and column separation

\section{O INTRODUCTION}

Entrapped air is a well-known phenomenon that gives rise to problems in almost any liquid pipeline system with sloped or undulated profiles (e.g. in hilly countries) and (even) flat profiles [1]. It may lead to high uncontrolled peak pressures with a potential risk of pipe rupture as well as considerably increases in energy losses. For this reason air valves are used to control the air flow in and out of the system (e.g. at high points) [2] and [3]. Although in practice the admission of air is not without problems, most of the problems are found during the release of entrapped air, sometimes resulting in pressures, even higher than if the air valves were not installed.

The function of air valves in pipeline systems is twofold: 1) to suppress sub-atmospheric pressures by admitting air rapidly (to avoid cavitation and column separation e.g. after transient events, flow interruptions, draining and system shut-down), and 2) to control the line pressures by releasing air slowly (to avoid high peak pressures e.g. during filling, system start-up). With respect to this dual-action the terms: 1) vacuum breaking valves and 2) air relief valves are commonly used. During the stage of air admission the existing subatmospheric pressures are suppressed. This event is accompanied with relatively small pressure surges (order of 1 bar or smaller) since the subatmospheric pressures can never be lower than the liquid vapour pressure. During the stage of air release the entrapped air is compressed and accelerated towards the air valve, together with the adjacent fluid column. The air compression may cause high pressure peaks (air valve slam) [4] to [8]. If all or most of the air is relieved from the system the air valve closes against the (still) accelerating fluid column. The reduction of the liquid velocity to zero (just before valve closure) is accompanied with additional pressure surges (order of 1 to 10 bar or higher), and possibly cavitation due to reflections of pressure waves. Under severe transient flow conditions the air valve may respond to pressure surges by reopening, possibly coupled with chatter (i.e. the repetitive opening and closure of a valve with high frequency) and other resonance effects in the system. In case of air valve failure during pressure transients column separation can occur in a pipeline system [9]. Column separation occurs in a pipe when the pressure drops to the liquid vapour pressure, assuming a negligible amount of free and released gas in the liquid [10] and [11]. This is usually the case in most industrial piping systems. Extremely large pressures may occur when the vapour cavities collapse, with a potential risk of severe engineering implications.

Research on the performance of air valves is traditionally achieved under quasi-steady flow conditions and on a rather small scale only. The lack of full (large) scale experimental data, as well as the dynamic character of the phenomena and complexity in the characterisation of two-phase flows, hinder the research progress in the mathematical modelling of the dynamic behaviour of air valves. Recent comprehensive experimental investigations in largescale test apparatus should lead to new understanding of the physical processes, dynamic scale laws and dynamic performance characterisation of air valves 
[12] and [13]. The main objective of the paper is to present the large-scale apparatus, test programme and some key results of dynamic flow tests performed at Deltares, Delft, The Netherlands [6], [9], [12] and [14]. Further, some measured and computational results are compared and discussed. The measurement data are stored on $\mathrm{CD}$ and available to readers by the corresponding author of this paper. The presentation of newly developed theoretical models is beyond the scope of this paper [6] and [14].

\section{EXPERIMENTAL APPARATUS}

The dynamic behaviour of air valves has been tested under controlled, dynamic flow conditions in a unique large scale test facility. To allow for the assessment of dynamic scale effects and the practical application of results, the tests were performed at full (large and medium) scale. The experimental work consisted of the following four types of tests: 1) steady flow tests with air, 2) dynamic tests with air release, 3) dynamic tests with air admission, and 4) dynamic tests with air admission and air release. During the dynamic tests the air valve was located at a high point in the test section. A number of dynamic tests were preceded by tests with closed air valve, in order to determine its effect on the line pressures. Float type air valves [1], with either metall ball or plastic cylinder floats, of 50 and $100 \mathrm{~mm}$ valve nominal diameter were tested.

\subsection{Steady Flow Tests with Air}

The steady flow tests with air were performed to determine the steady flow characteristics of the air valves. The relation between the air flow rate and pressure drop across the valve was measured at different (fixed) air valve float positions. The test set-up is shown in Fig. 1. A large, compressed air, reservoir (volume $70.7 \mathrm{~m}^{3}$ ) with a maximum pressure of $22.5 \mathrm{bar}$, fed air into a $200 \mathrm{~mm}$ test section, with the air valve mounted at the end.

Two vortex flowmeters (Foxboro, USA) of diameter 25 and $200 \mathrm{~mm}$ were installed and used depending on the flow range. The data acquisition system recorded pressures at the valve and flowmeters, $\Delta p$ across air valve, water temperature at flowmeter, and vortex frequency of the flowmeter. The sampling frequency for each recorded signal was $f_{s}=20 \mathrm{~Hz}(0.05 \mathrm{~s}$ between samples $)$. The duration of the measurements was 30 (most of the tests), 20 or $15 \mathrm{~s}$ depending on the flow rate. Each test started after a steady air flow was established. The air valve characteristics were measured at valve openings of 100 (fully opened), 75,50 and $25 \%$, by fixing the float position. The air valves were tested in two flow directions, to enable air admission and air release. For this purpose, the valve was mounted in two opposite directions. All experiments have shown a high degree of repeatability of the measured pressures and flow velocities.

\subsection{Dynamic Tests with Air Release and Dynamic Tests with Air Admission}

A modified test rig for check valves (Fig. 2) was used to test the dynamic performance of industrial size, float type air valves, during air release or during air admission. Two test configurations, with pipe diameters of 200 and $500 \mathrm{~mm}$, were used for DN50 and DN100 air valves, respectively. The entire 200 and $500 \mathrm{~mm}$ test sections were geometrically similar in order to assess scale effects on the dynamic valve behaviour. Basically, the apparatus consists of a large air reservoir, a fast operating on/off valve, a pressurised tank, and a sloped test section. The large air reservoir was used to pressurise the tank (air release tests) or to

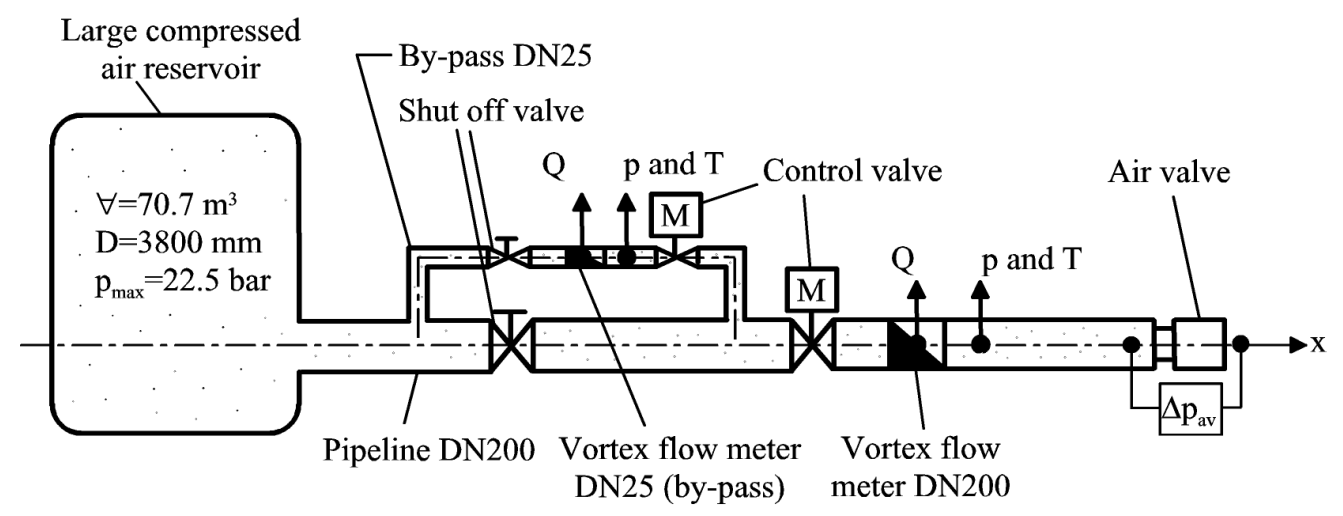

Fig. 1. Air loop test rig 
depressurise it (air admission tests). The fast operating $300 \mathrm{~mm}$ butterfly valve on top of the tank was used to produce rapid transients. In advance of each test the vent valve was used to control the initial water level in the pressurised tank and sloped test section. At the T-junction on top of the sloped test section, a butterfly valve was installed (Fig. 2), to allow for the simulation of two pipeline configurations (only used for air release tests). When it was closed, the air valve was located at the end of the pipeline. In this case the amount of residual air (air that remains in the system after air valve closure) was relatively small. On the other hand, when it was open, the first closing of the air valve occurred long before the air was completely discharged from the pipe. In that case the scatter in the results increased considerably. The explanation for this scatter can be found in the boundary conditions and the low reproducibility of the amount of residual air.

In the design of the test configuration several variables were identified as critical in the transient events: pressure, flow rate, air-water interface, float movement and temperature. Care must be taken in the selection of instrumentation (accuracy, frequency response) to be used in water hammer and column separation measurements [15] to [17]. All instrumentation, including pressure transducers and electromagnetic flow meters (200 and $500 \mathrm{~mm}$ ), were carefully calibrated prior and after the dynamic tests. The location of pressure transducers $\left(p_{E M F}, p_{p s}\right.$ and $\left.p_{a v}\right)$, six photocells $\left(F_{1}\right.$ to $\left.F_{6}\right)$, displacement transducer $\left(s_{a v}\right)$, temperature transducer $(T)$ and electromagnetic flow meter $\left(Q_{E M F}\right)$ is shown in Fig. 3, for both the 200 and $500 \mathrm{~mm}$ test sections. The sampling frequency for each recorded signal was $f_{s}=1000$ $\mathrm{Hz}$. The dynamic pressure transducers used (Kistler $410 \mathrm{~B}$ ) had a frequency response as high as $50 \mathrm{kHz}$. Nevertheless, the main concern was the frequency response of the electromagnetic flow meter available in the laboratory, since there is not an easy procedure for a dynamic calibration of this type of devices. This special dynamic meter was successfully used in previous studies to characterise the dynamic response of the check valves [17] to [19]. The six photocells were installed along the sloped pipe to detect the airwater interface. A fast response analogue (HBM W

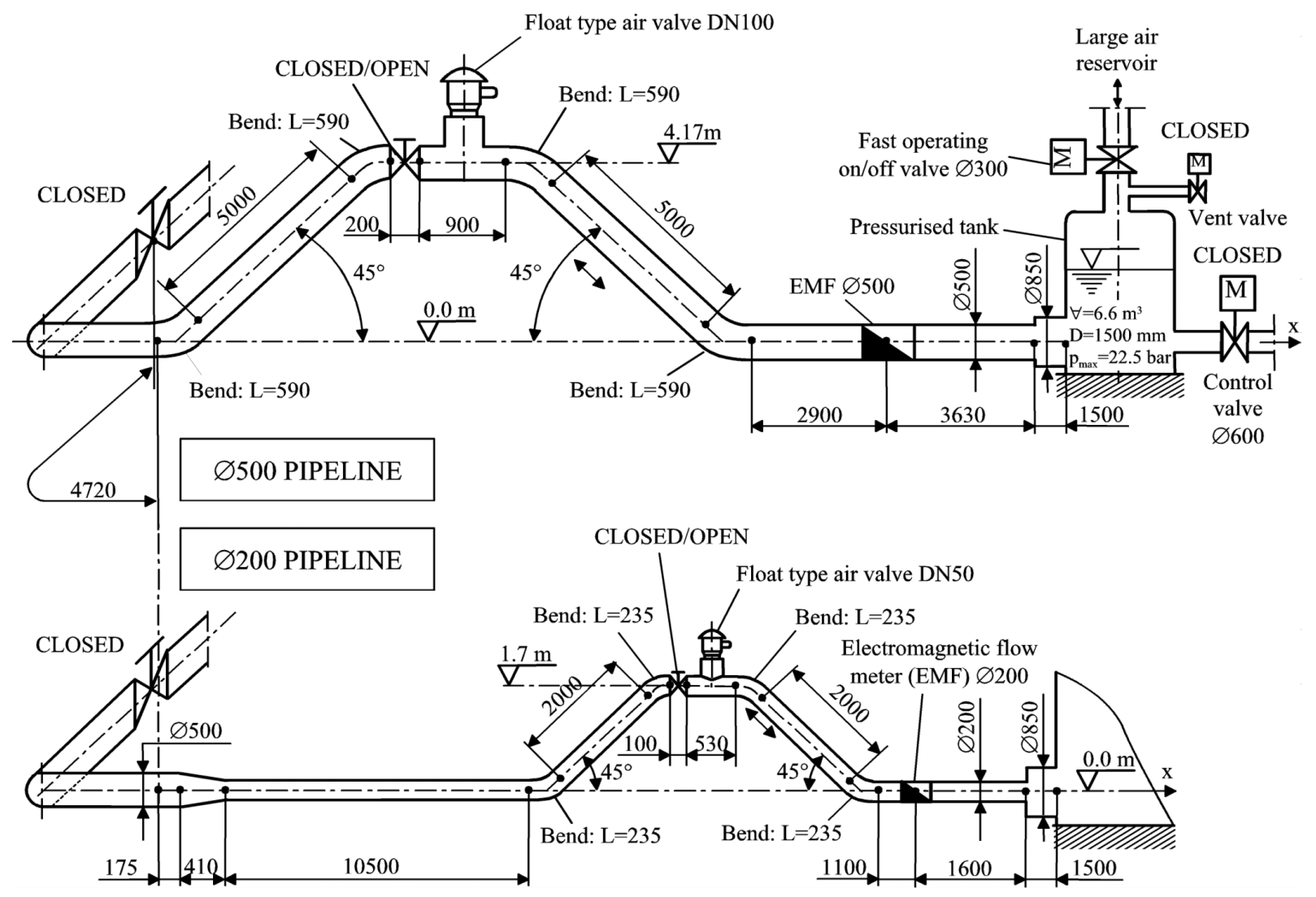

Fig. 2. Modified test rig for check valves with 200 and $500 \mathrm{~mm}$ test sections 


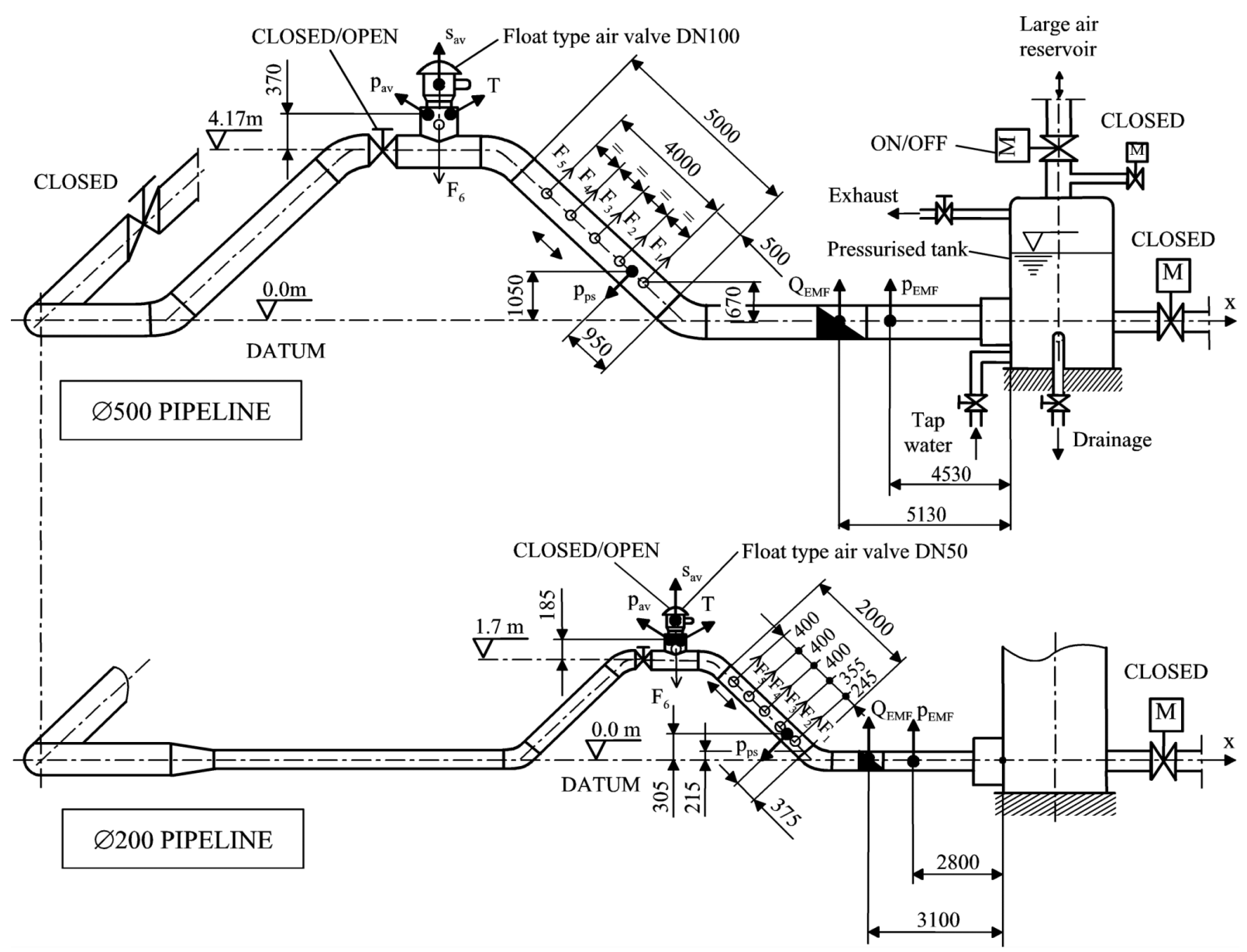

Fig. 3. Test sections of modified test rig for check valves with instrumentation

50) displacement transducer was fitted to the air valve float to detect its vertical position. A temperature transducer was installed at the air valve T-section to measure the fluid temperature.

The test programme was subdivided into (a) air release and (b) air admission tests.

(a) Air release tests. The air valve responds to the controlled overpressure above atmospheric pressure, by which a certain amount of entrapped air is accelerated towards the valve. Consequently, the air valve starts to release air. Tests were performed at different entrapped air volumes and at different initial overpressures, resulting in different flow acceleration rates. The average acceleration of the water column measured from the instant it starts moving until it reaches the air valve adopted values from 0.19 up to $0.78 \mathrm{~m} / \mathrm{s}^{2}$. In order to accelerate the water column, a large-capacity $\left(70.7 \mathrm{~m}^{3}\right)$ air reservoir was pressurised with a compressor. The overpressures needed to produce the abovementioned accelerations ranged from 0.17 up to 0.28 bar. A dynamic test was initiated by opening the fast acting valve on top of the pressurised tank (Fig. 2). Because of the quick response of the fast operating on/off valve (opening time $0.1 \mathrm{~s}$ ), the pressurisation was almost instantaneous. Due to the large size of the air reservoir the pressure at the pressurised tank was almost constant during the experiments. As a result the test section was suddenly pressurised to the desired level, the water column was accelerated towards the air valve at the top and the entrapped air in the pipe was relieved through the air valve. The velocity of the water column at the instant that the air valve starts closing ranged from 0.69 up to $1.92 \mathrm{~m} / \mathrm{s}$.

(b) Air admission tests. The air valve responds to the controlled underpressure (below atmospheric pressure). Consequently, the air valve starts to admit air. In advance of each test the test section (Fig. 2) was completely filled with water and the large air reservoir was depressurised by means of a vacuum pump. A test was initiated by opening the fast acting valve on top of the pressurised tank, which brought the water 


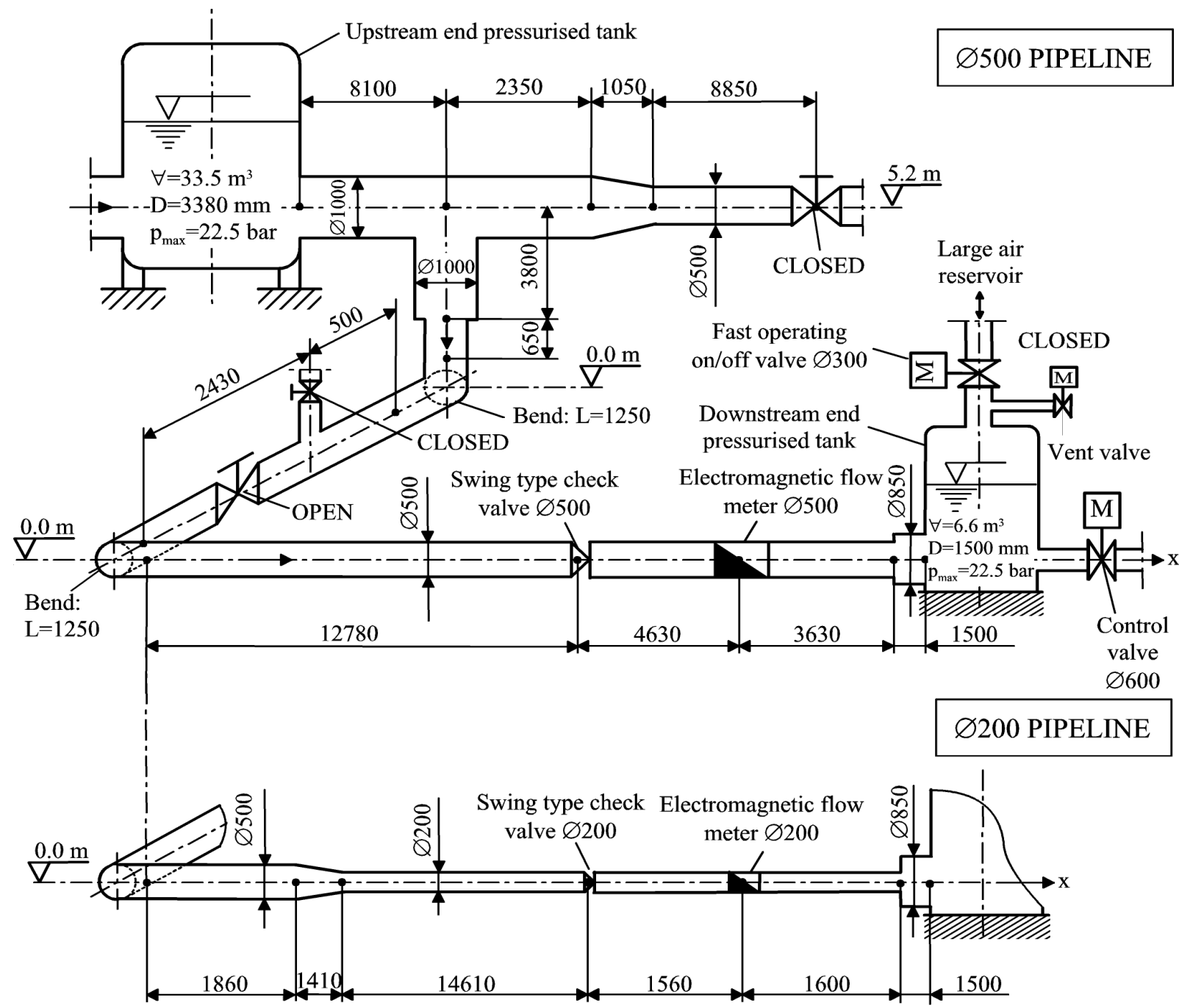

Fig. 4. Test rig for check valves with 200 and $500 \mathrm{~mm}$ test sections

column into motion. By controlling the underpressure in the large air reservoir it was possible to conduct tests at different water column accelerations. The underpressures ranged from -0.15 up to -0.42 bar.

\subsection{Dynamic Tests with Air Admission and Air Release}

The test rig for check valves shown in Fig. 4 was used to investigate the effect of air valves on cavitation and column separation. Two types of tests were performed: (a) tests with no air valve (Fig. 4) and (b) tests with air valve (Fig. 5). The air valve was installed immediately upstream of the check valve, to investigate its dynamic response to cavitation and column separation, as induced by the check valve closure. In order to study dynamic scale effects, two similar sections with industrial size of 200 and 500 $\mathrm{mm}$ diameter pipes were used. The apparatus consists of an upstream end pressurised tank, horizontal test section with check valve, downstream end pressurised tank, connected to a large air reservoir, and a control valve. The check valves used were undamped swing types with nominal diameters of 200 and $500 \mathrm{~mm}$ and actual discharge (bore) diameters of 154 and $405 \mathrm{~mm}$, respectively. The air valves were double orifice float types with diameters of 50 and $100 \mathrm{~mm}$, respectively; the small orifice was blocked during all tests. The geometrical similarity of the 200 and 500 $\mathrm{mm}$ T-junction test insertions and the two air valves was fair.

The test procedure was as follows. The steady state flow conditions (in advance of a dynamic test) were controlled by a control valve (600 $\mathrm{mm}$ diameter). 


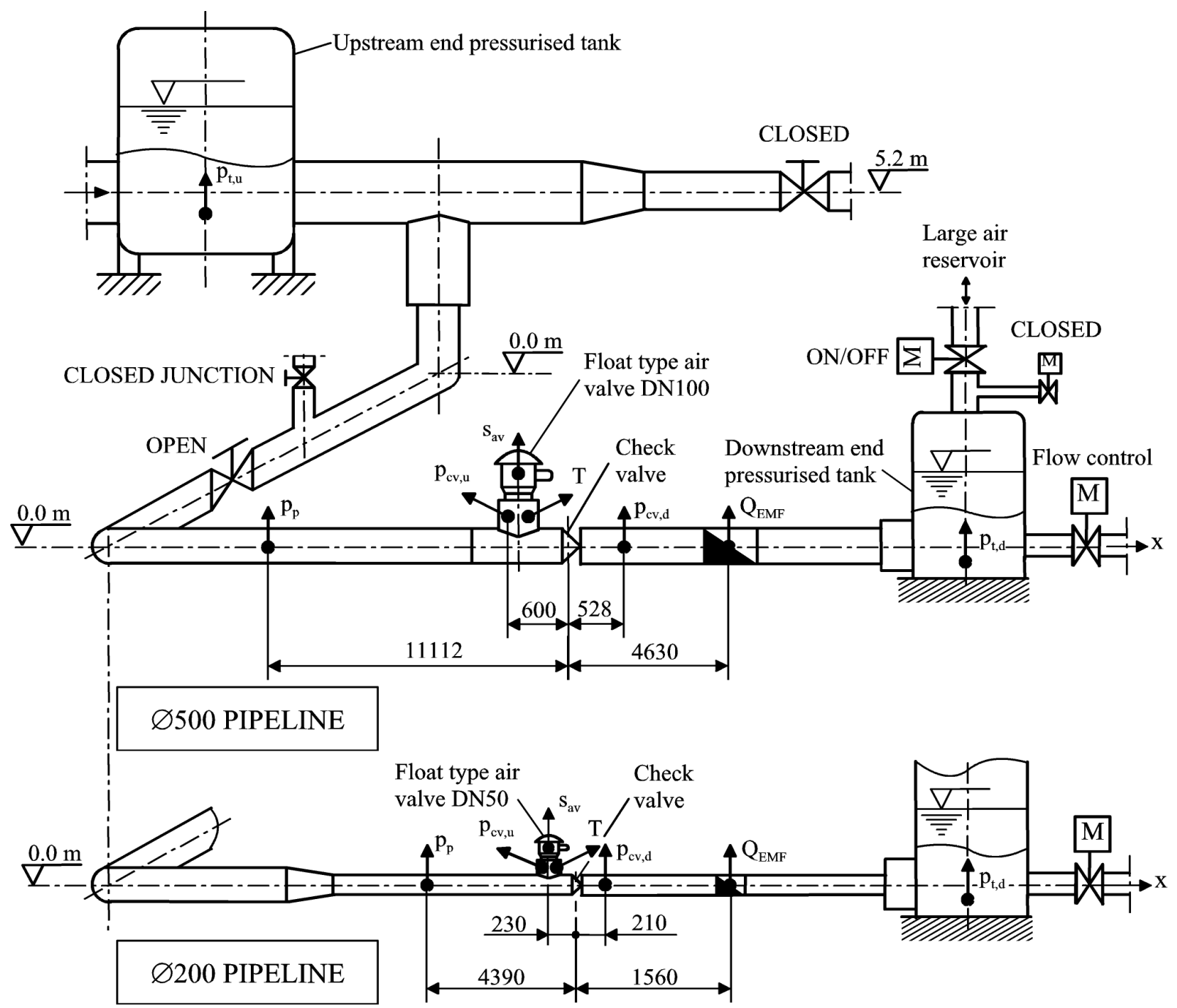

Fig. 5. Test rig for check valves with 200 and $500 \mathrm{~mm}$ test sections with air valve and instruments

The water level in the downstream end pressurised tank was adjusted by the vent valve. From initial steady flow conditions, a transient event was initiated by opening the fast operating on/off valve (diameter $300 \mathrm{~mm}$ ) on top of the tank. The high-pressure air from the large air reservoir rapidly increased the downstream pressure. Consequently, the flow in the test section was decelerated, the check valve closed after flow reversal, and pressure surges were generated. Column separation occured at the upstream side of the check valve, when the pressure dropped to the vapour pressure. The degree of cavitation was controlled by the flow deceleration imposed upon the check valve. The events of air admission and subsequent air release were followed by an air valve closure with pressure surges.
In Fig. 5 the location of the instruments in the 200 and $500 \mathrm{~mm}$ test sections is shown. The sampling frequency for each recorded signal was $f_{s}=2000 \mathrm{~Hz}$. The check valve opening (disc position) could not be measured due to design constraints. Pressures $p_{p}, p_{c v, u}$, $p_{c v, d}$ and $p_{t, d}$ were measured with Kistler $410 \mathrm{~B}$ high frequency $(50 \mathrm{kHz})$ piezoelectric pressure transducers. Pressures $p_{t, u}$ and $p_{c v, u}$ (parallel measurement) were measured by Statham PD high accuracy absolute strain-gauge pressure transducers. All pressure transducers were flush mounted to the inner pipe wall. The measured results confirmed the fast response of both electromagnetic flow meters. A fast response Hottinger (HBM) W 50 analogue displacement transducer, fitted to the air valve float, was used to measure the vertical float position. The location of 
instruments in the respective test sections without and with air valve was practically the same. Temperature $T$ and air valve opening $s_{a v}$ (float position) were not measured during the test series without air valve.

The test programme was subdivided into (a) tests with no air valve in the system and (b) tests with dualacting vacuum breaking/air relief valve positioned at the upstream end of the check valve.

(a) Tests without air valve. Water hammer and column separation measurements in the $200 \mathrm{~mm}$ test section were carried out with steady state (initial) velocity $V_{0}=1.02 \mathrm{~m} / \mathrm{s}$ (about $20 \%$ above the critical flow velocity at which the check valve is just fully open) and static pressure in the system of $0.3 \mathrm{MPa}$. The intensity of transients was controlled by the magnitude of the mean deceleration $|\mathrm{d} V / \mathrm{d} t|$ of the liquid column during the check valve closure event. The mean $|\mathrm{d} V / \mathrm{d} t|$ was in the range from 0.55 to 3.93 $\mathrm{m} / \mathrm{s}^{2}$, and the corresponding reverse flow velocity $V_{R}$ from about 0.08 to $0.22 \mathrm{~m} / \mathrm{s}$. Some measurements were performed with an additional pressure transducer at the closed-junction $21.56 \mathrm{~m}$ upstream of the check valve (see Fig. 5). The idea was to investigate how far the pressure at the assumed upstream boundary of the $200 \mathrm{~mm}$ test section (i.e. the tapered junction DN500/ DN200) is constant. The measured results showed that this boundary in first approximation may be modelled as a constant head boundary in numerical analysis. In this case the mean $|\mathrm{d} V / \mathrm{d} t|$ was in the range from 0.42 to $4.08 \mathrm{~m} / \mathrm{s}^{2}$, and the corresponding $V_{R}$ from about 0.05 to $0.21 \mathrm{~m} / \mathrm{s}$. Measurements in the $500 \mathrm{~mm}$ test section were carried out with $V_{0}=1.06 \mathrm{~m} / \mathrm{s}$ (about $20 \%$ above the critical flow velocity) and static pressure of 0.3 MPa. The mean $|\mathrm{d} V / \mathrm{d} t|$ was in the range from 0.63 to $3.70 \mathrm{~m} / \mathrm{s}^{2}$, and the corresponding $V_{R}$ from 0.26 to 1.15 $\mathrm{m} / \mathrm{s}$.

(b) Tests with air valve. The objective of these measurements was to investigate to what extent the air valve suppresses column separation in pipelines. Dynamic tests in the $200 \mathrm{~mm}$ test section were carried out with $V_{0}=1.02 \mathrm{~m} / \mathrm{s}$ and static pressure of $0.3 \mathrm{MPa}$. The $|\mathrm{d} V / \mathrm{d} t|$ was in the range from 0.81 to $4.24 \mathrm{~m} / \mathrm{s}^{2}$, and the corresponding $V_{R}$ from about 0.10 to 0.23 $\mathrm{m} / \mathrm{s}$. Dynamic tests in the $500 \mathrm{~mm}$ test section were performed with $V_{0}=1.06 \mathrm{~m} / \mathrm{s}$ and static pressure of $0.3 \mathrm{MPa}$. The mean $|\mathrm{d} V / \mathrm{d} t|$ was in the range from app. 0.60 to $3.70 \mathrm{~m} / \mathrm{s}^{2}$, and the corresponding $V_{R}$ from app. 0.26 to $1.15 \mathrm{~m} / \mathrm{s}$.

\subsection{Uncertainty Analysis}

The uncertainty of a measurement may be represented by the sum of bias and precision errors. The rootsquare-sum (RSS) uncertainty $U_{x}$ is expressed as:

$$
U_{x}=\sqrt{B^{2}+P_{x}^{2}},
$$

where $B$ and $P_{x}$ are bias and precision errors, respectively [20]. The bias error is the fixed, systematic error, which is usually constant for each measurement. The precision error is the random error which results in data scatter in experiments. Table 1 shows a list of uncertainties $U_{x}$ in the measurement. The uncertainties are given either as absolute values (same units as quantity) or as percentage (uncertainty/ quantity $\times 100 \%$ ) values, where appropriate. The repeatability of identical experimental runs, performed in both the 200 and $500 \mathrm{~mm}$ test sections, was investigated. The objective of the repeatability tests is to estimate the data scatter (precision error) due to an inability to reset the system to identical initial conditions. A comparison of results between 'identical' runs show that the magnitude and timing of the bulk pressure pulses are repeatable, whereas some high frequency pressure spikes do not exhibit repeatability.

Table 1. Estimated uncertainties in the measurement

\begin{tabular}{lc}
\hline Quantity & Uncertainty \\
\hline Pipe internal diameter & $\pm 0.1 \mathrm{~mm}$ \\
\hline Pipe length & $\pm 0.01 \mathrm{~m}$ \\
\hline Piezoelectric pressure transducer & $\pm 0.7 \%$ F.S. \\
\hline Strain-gauge pressure transducer & $\pm 0.3 \%$ F.S. \\
\hline Electromagnetic flow meter DN200 & $\pm 2 \%$ of rate \\
\hline Electromagnetic flow meter DN500 & $\pm 4 \%$ of rate \\
\hline Water temperature & \pm 0.5 oC \\
\hline Air-valve float position & $\pm 0.5 \%$ F.S. \\
\hline
\end{tabular}

\section{CASE STUDY: AIR RELEASE EVENT WITH AIR VALVE SLAM}

The objective of this case study is to investigate the air release event in an industrial size DN500 sloping pipe test section with installed DN100 cylindrical float type dual-acting vacuum breaking/air relief valve at the top of the pipe (Section 1.2). The test section with air valve and instruments is given in Fig. 3. Basically, the experiment simulates the filling of a pipe partially filled with water, with an air pocket at its end. In the initial stage, the air valve is open and the air pressure inside the pipe is atmospheric. The initial water level in the inclined pipe was $3.80 \mathrm{~m}$ above datum level 
(Fig. 3). The corresponding initial volume of the air pocket was $0.334 \mathrm{~m}^{3}$, (with the butterfly valve near the air valve closed). The pressure difference between the large air reservoir and pressurised tank was $21.5 \mathrm{kPa}$. The temperature measured at the air valve (see Fig. 3) was $T=18.8{ }^{\circ} \mathrm{C}$ and remained constant during the test. The transient event was initiated by opening the fast operating on/off valve on the top of the pressurised tank (Fig. 3). Due to the pressure difference the water column is accelerated towards the air valve. When the water front reaches the air valve, its float moves up, and the valve closure results in a rapid flow velocity change/reduction. This water hammer effect, together with the compression of residual air inside the pipe, produces a large pressure rise (air valve slam). In this stage of the transient the entire pipe is filled with water, except near the air valve, where small air pockets remain entrapped.
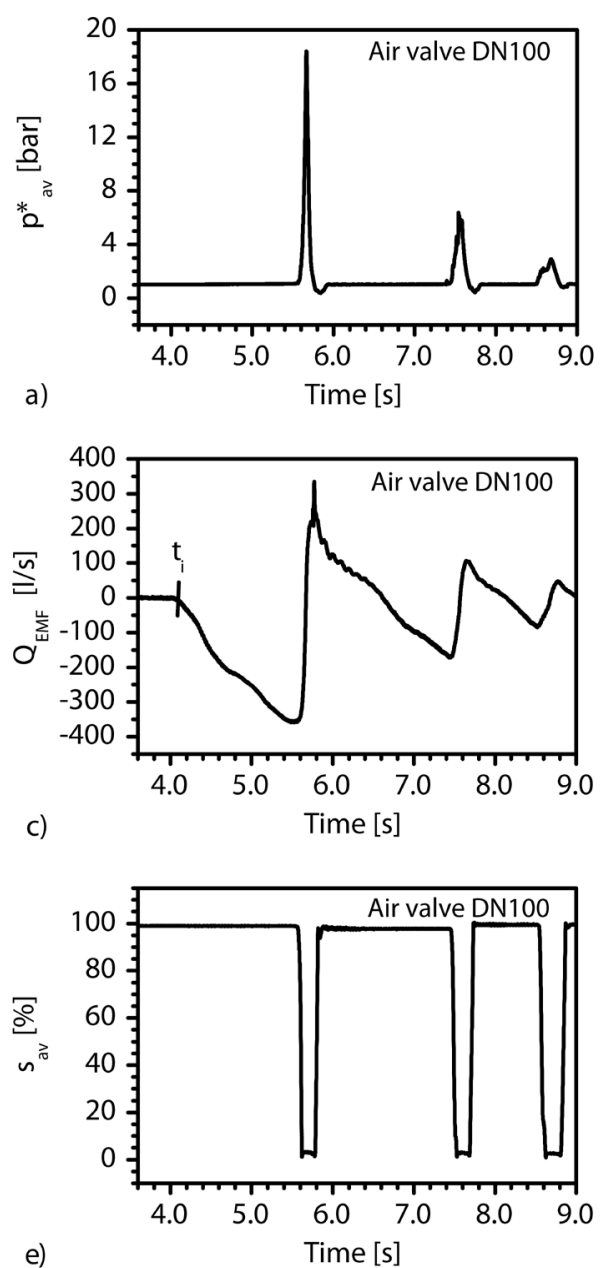

A typical result of a release test is shown in Fig. 6 where the time histories of the pressure $p^{*}{ }_{a v}$, the water flow rate $Q_{E M F}$ and the air valve float displacement $s_{a v}$ are presented. Each signal is depicted at two time scales; the smaller scale at the right side allows for a more detailed observation of the events.

Initial event: The water column starts moving at the instant of initiation (Fig. $6 \mathrm{c}, t_{i}=4.11 \mathrm{~s}$ ) and is accelerated towards the air valve. The photocell at the air valve $F_{6}$ (Fig. 3) detected the water-air interface at time $t=5.50 \mathrm{~s}$ (registered as a change of signal). There are no significant pressure changes until the instant of pressure rise at time $t_{p}=5.56 \mathrm{~s} \mathrm{(Fig.} \mathrm{6b).}$ The time interval $\left[t_{i}, t_{p}\right]$ is defined as initial event [6]. During this event rigid column theory is valid.

Air compression event: Subsequently air compression takes place. Three stages may be distinguished here, with fully opened, partly opened
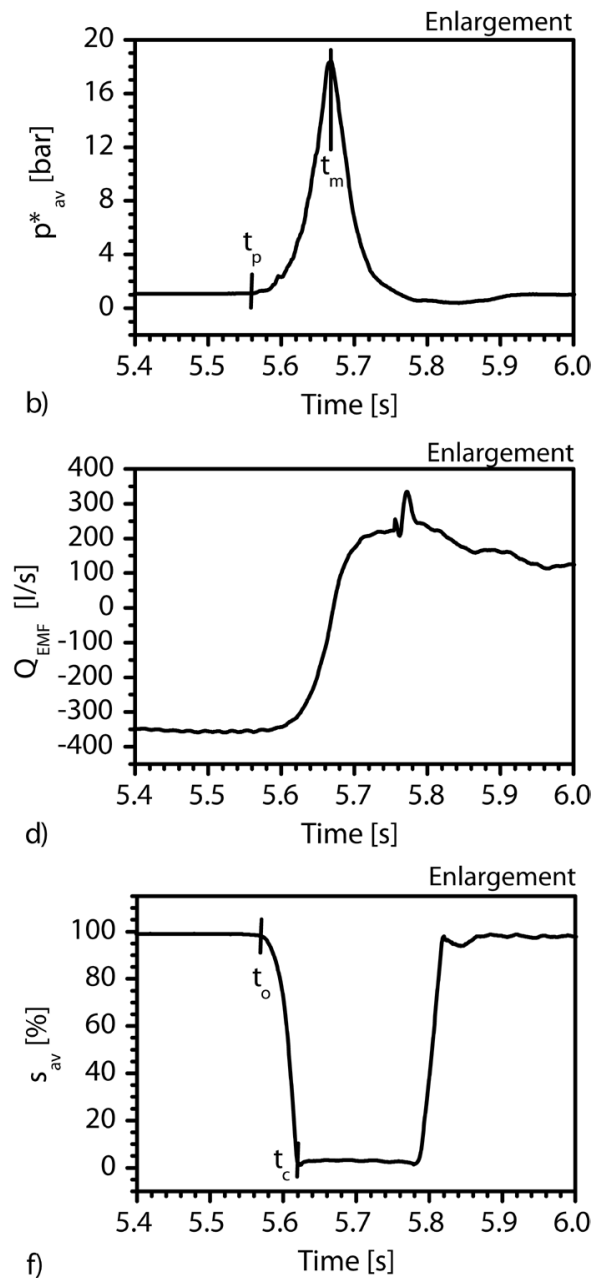

Fig. 6. Air release test in $500 \mathrm{~mm}$ test section with air valve slam; a) and b) pressure at the air valve $\left.\left(p^{*}{ }_{\text {av }}\right), \mathrm{c}\right)$ and d) discharge $\left(Q_{E M F}\right)$ at electromagnetic flow meter position and e) and f) air valve opening ( $\left.\mathrm{s}_{\mathrm{av}}\right)$ 
(closing) and fully closed air valve (Figs. 6e and f). The air valve starts closing at time $t_{o}=5.57 \mathrm{~s}$. After the instant of air valve closure at time $t_{c}=5.62 \mathrm{~s}$, the residual of air is further pressurised until the maximum pressure $p^{*}{ }_{a v, \max }=18.4$ bar is reached at time $t_{m}=5.67$ s (Figs. 6a and b). At this instant the water column is brought to a rest (Figs. $6 \mathrm{c}$ and d; $Q_{E M F}=0 \mathrm{~m}^{3} / \mathrm{s}$ ) and then reverses from the air valve. The pressure rise is relatively high, while the duration of this event is relatively short. The time interval $\left[t_{p}, t_{m}\right]$ is defined as air compression event [6]. Thermodynamics, aerodynamics and elastic waterhammer theory are valid.

Residual air: The residual air, which remains inside the pipe system after valve closure, which plays a significant role in the water transient magnitude, can be indirectly evaluated with an acceptable uncertainty, by integrating the flow signal. For the evaluation of the residual air mass it is referred to Kruisbrink et al. [6].

Pressure surges: The flow velocity at the end of the initial event (at time $t_{p}$ ) is defined as the terminal velocity $\left(V_{p}\right.$ when based on pipe diameter and $v_{p}$ when based on air valve diameter). At this instant the flow rate reaches its maximum value. After this instant the flow is reduced to zero, which results in a pressure rise. According to water hammer theory, the terminal velocity is proportional to the pressure rise and may therefore be used to estimate the pressure surges, induced by the air valve closure.

\section{CASE STUDY: WATER HAMMER AND COLUMN SEPARATION WITH AIR VALVE}

The objective of this case study is to investigate transient event with water hammer and column separation in an industrial size DN500 horizontal pipe test section with installed DN100 cylindrical float type dual-acting vacuum breaking/air relief valve (Section 1.3). The test section with air valve and instruments is given in Fig. 5. A typical result of a column separation test is shown in Fig. 7. The steady state (initial) flow velocity in pipe was $V_{0}=$ $1.06 \mathrm{~m} / \mathrm{s}$ and the static line pressure was about 0.3 $\mathrm{MPa}$. The transient event was initiated by opening the fast operating on/off valve on top of the downstream end tank (Figs. 4 and 5) at the time of $t=1.53 \mathrm{~s}$ (Fig. $7 \mathrm{~d})$. The compressed air from the large air reservoir with a higher set pressure than in the horizontal pipe test section increased the pressure in the downstream end tank for about 1.4 bar. The flow in the test section was decelerated at a rate of about $|\mathrm{d} V / \mathrm{d} t|=3.6 \mathrm{~m} / \mathrm{s}^{2}$ (Fig. 7e). The check valve was closed after the flow reversal generating column separation at the upstream end of the valve (pressure dropped to the liquid vapour pressure - see Figs. 7a and b) and the pressure rise of 9.2 bar at the downstream end of the valve (Fig. 7c). Initialy a large vapour cavity was created at the valve. Air valve opened with a time delay of 20 milliseconds and it stayed open for 110 milliseconds. The pressure in the large cavity increased to the atmospheric pressure of 70 milliseconds after pressure dropped to the liquid vapour pressure (effective time to fill the vapour cavity with air). A discrete vaporous cavitation zone (small void fraction) may be observed along the pipeline (Fig. 7a). The maximum absolute pressure due to the collapse of the large gas cavity at the upstream side of the check valve $\left(p^{*}{ }_{c v, u}\right)_{\max }=$ 10.2 bar occurred about 10 milliseconds after the air valve was completely closed. A closed check valve reopened when the pressure difference across the valve exceeded a threshold value $\left(p_{c v, u}>p_{c v, d}\right)$ and this occurred at the time of cavity collapse. Consequently, the partly opened check valve reduced the propagating pressure pulse. The measured temperature at the T-junction with air valve (see Fig. 5) was $T=23.3$ ${ }^{\circ} \mathrm{C}$ and it remained constant during the considered transient event. The same holds true for the pressure in the upstream end pressurised tank. This case study clearly shows the delay of the valve opening when pressure drops to liquid vapour pressure and the time shift between air valve closure and pressure rise due to gas cavity collapse. The valve response is not instantaneous as traditionally assumed in the standard theoretical models used for transient analysis.

\subsection{Effect of Air Valve on Surge Suppression}

The effect of the air valve as a surge suppression device is studied. For this purpose tests without and with air valve are compared, as performed in the $500 \mathrm{~mm}$ test section (Figs. 4 and 5). In Fig. 8 the results of Fig. 7 are presented, together with results of a test without air valve performed under identical flow conditions. Investigation of pressures (absolute) in the upstream pipe $\left(p^{*}\right)$ and at the check valve $\left(p^{*}{ }_{c v, u}\right.$ and $\left.p^{*}{ }_{c v, d}\right)$ shows that in the first instance the air valve hardly has any effect on the sudden pressure surges induced by the check valve closure. This may be attributed to the above-mentioned delay in its response. In the second instance however, the pressure surges are strongly reduced, while a further occurence of cavitation (i.e. at vapour pressure) is avoided. The air valve acts here as a surge protection device, i.e. it suppresses pressure surges, avoids cavitation (potential risk of pipe collapse) and it attenuates 

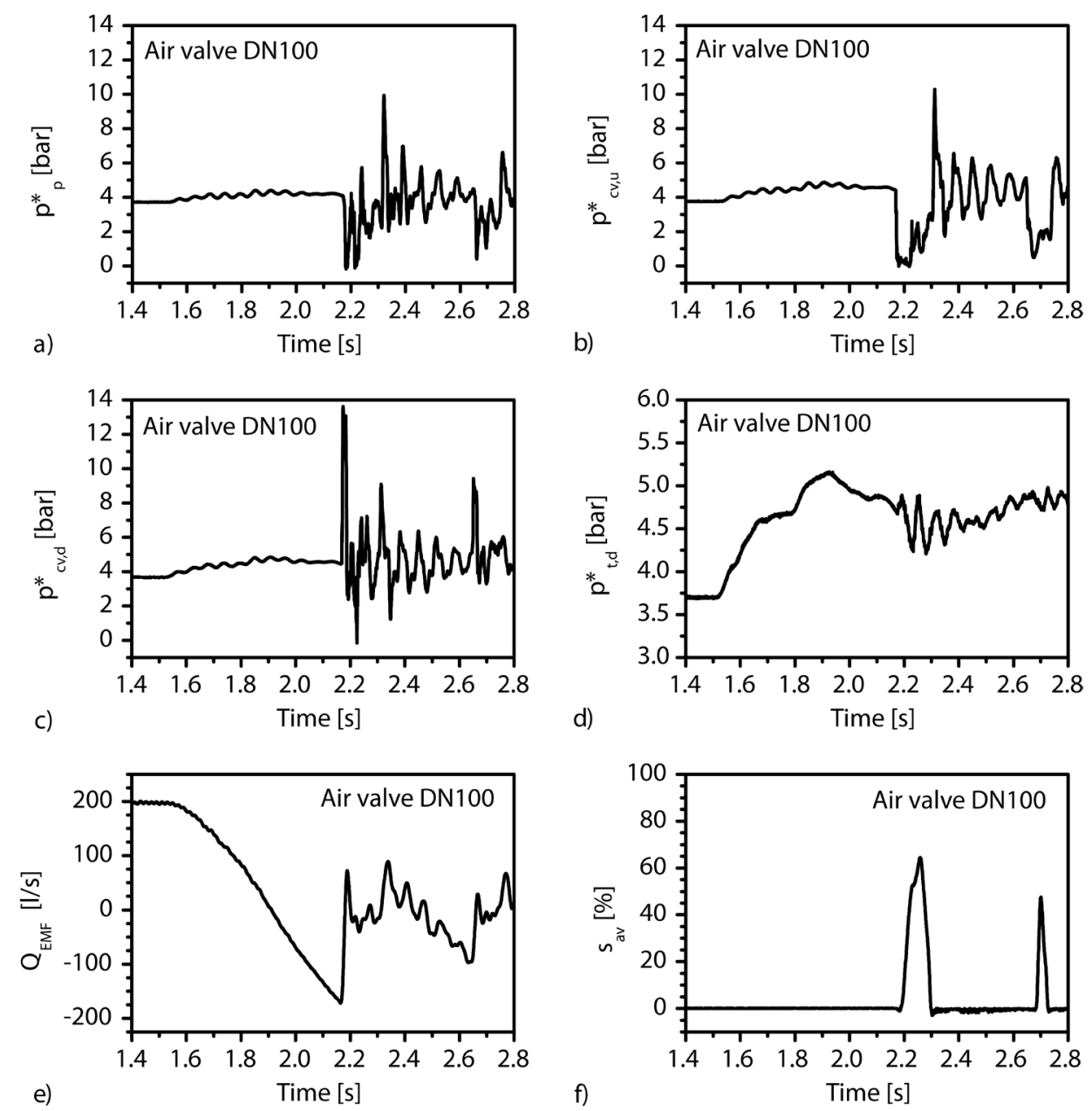

Fig. 7. Column separation test in $500 \mathrm{~mm}$ test section with air valve; a) pressures along the pipe $\left.\left(p^{*}{ }_{p}\right), b\right)$ and c) at the check valve $\left(p^{*}{ }_{c v, u}\right.$ and $\left.\left.p_{c v, d}^{\star}\right), d\right)$ in the downstream end pressurised tank $\left.\left(p^{*}, d\right), e\right)$ discharge $\left(Q_{E M F}\right)$ at electromagnetic flow meter position and f) air valve opening $\left(s_{a v}\right)$

pressure oscillations (a potential risk of pipe rupture). The surge protetion device should alter the system characteristics and consequently, the intensity of the flow velocity changes in the system [1], [10] and [21].

\subsection{Comparison of Test and Simulation with Simple Air Valve Model}

Recently an attempt was made to compare and discuss the measured and the computational results for a number of experimental runs in the considered test rig for check valves without (Fig. 4) and with an air valve (Fig. 5) [14]. A set of water hammer and column separation equations was solved using the Godunov's method [14] and [22]. The numerical model includes constant pressure upstream end reservoir, pipe test section and downstream end boundary. The test section of total length $L=30.76 \mathrm{~m}$ from the upstream end pressurised tank to the check valve (downstream end boundary condition) was considered in numerical simulations. The air valve was modelled as a simple source term. The air mass flow through the air valve (in or out) was assumed constant with cushioning at the end of the releasing period. The check valve was modelled as a downstream end boundary condition (i) as a dead end when the check valve was closed and (ii) by applying the measured pressure and flow rate history downstream the check valve when the check valve was opened. The time step in the simulation was 0.0001 s. In Fig. 9 results of a simulation are presented together with the test results of Fig. 7, showing the measured and calculated pressures along the upstream pipe $\left(p_{p}^{*}\right)$ and at the check valve $\left(p^{*}{ }_{c v, u}\right)$. The agreement between test and simulation is reasonable, bearing in mind that the transient flow, induced by the 

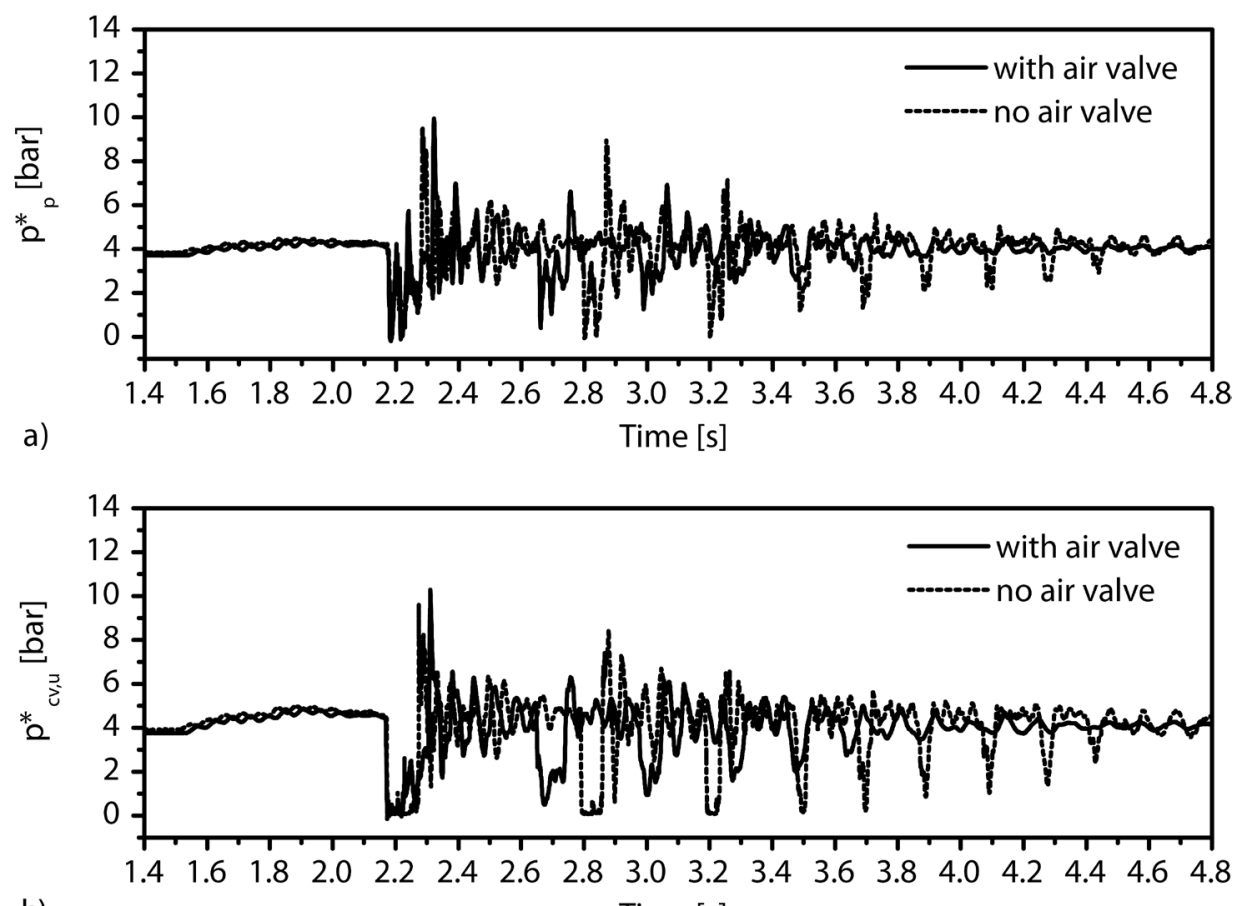

b)

Time [s]

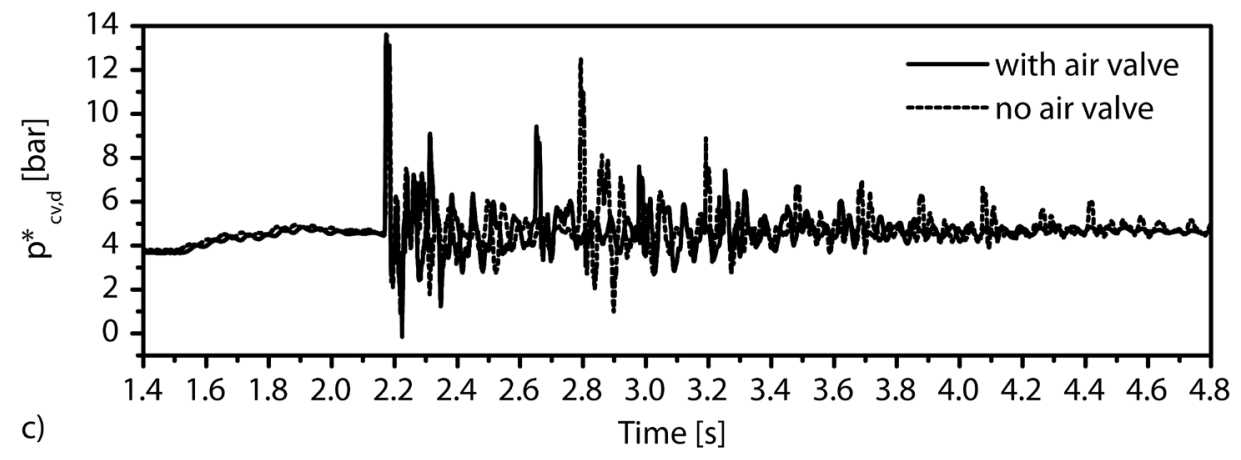

Fig. 8. Column separation tests in $500 \mathrm{~mm}$ test section with and without air valve; a) pressures along the pipe ( $p^{*}$ ), b) and c) at the check valve $\left(p^{\star}{ }_{c v, u}\right.$ and $\left.p{ }_{c v, d}\right)$
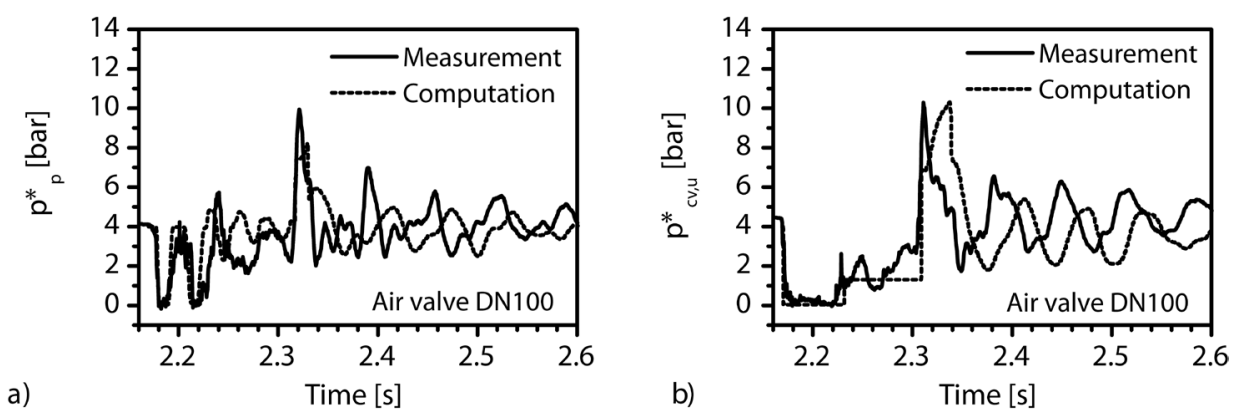

Fig. 9. Column separation test in $500 \mathrm{~mm}$ test section with air valve; a) comparison of measured and calculated pressures along upstream pipe $\left(p^{*}\right)$ and $\left.b\right)$ at the check valve $\left(p^{*}{ }_{c v, u}\right)$ 
dynamic behaviour of both the air valve and check valve, is complex.

\section{CONCLUSIONS}

The dynamic behaviour of air valves has been tested under controlled, dynamic flow conditions in a unique large scale test facility at Deltares, Delft, the Netherlands. The tests were performed at full (large and medium) scale in geometrically similar test sections, to allow for the assessment of dynamic scale laws and the practical application of results. The experimental work consisted of the following four types of tests: 1) steady flow tests with air, 2) dynamic tests with air release, 3) dynamic tests with air admission, and 4) dynamic tests with air admission and air release. During the dynamic tests the air valve was located at a high point in the test section. The approach to determine the dynamic behaviour of air valves was to measure their response to different flow accelerations towards (air release) and from the air valve (air admission). In this way, the valve behaviour following events like system start-up, pump trip or pipe rupture is simulated.

In two case studies some key results of the dynamic flow tests are presented and discussed. The air release tests show that the closure of air valves may result in significant pressure peaks (up to the order of 10 bar), possibly followed by air valve slam, while some residual air remains entrapped in the system. The column separation tests reveal a delay in valve response to sudden underpressures. Although the delay in the valve opening is relatively short (order of $0.01 \mathrm{~s}$ ), it does not prevent the occurence of cavitation, when the pressure suddenly drops to the liquid vapour pressure. After a delayed air admission however, the cavitation disappears and pressure surges are strongly reduced, although the valve closure also here is accompanied with pressure peaks. The response of the valve is not instantaneous as traditionally assumed in literature on transient flow in liquid-filled pipelines. Column separation tests with and without air valve show a benifical effect of the air valve as surge supression device. Only when properly designed, dimensioned and installed in the pipe system, the air valve may act as surge protection device.

\section{ACKNOWLEDGMENTS}

The authors gratefully acknowledge the support of the European Commission for their funding of the Transnational Access to Major Research Infrastructure activity within the Improving Human Potential (IHP) Programme.

\section{NOMENCLATURE}

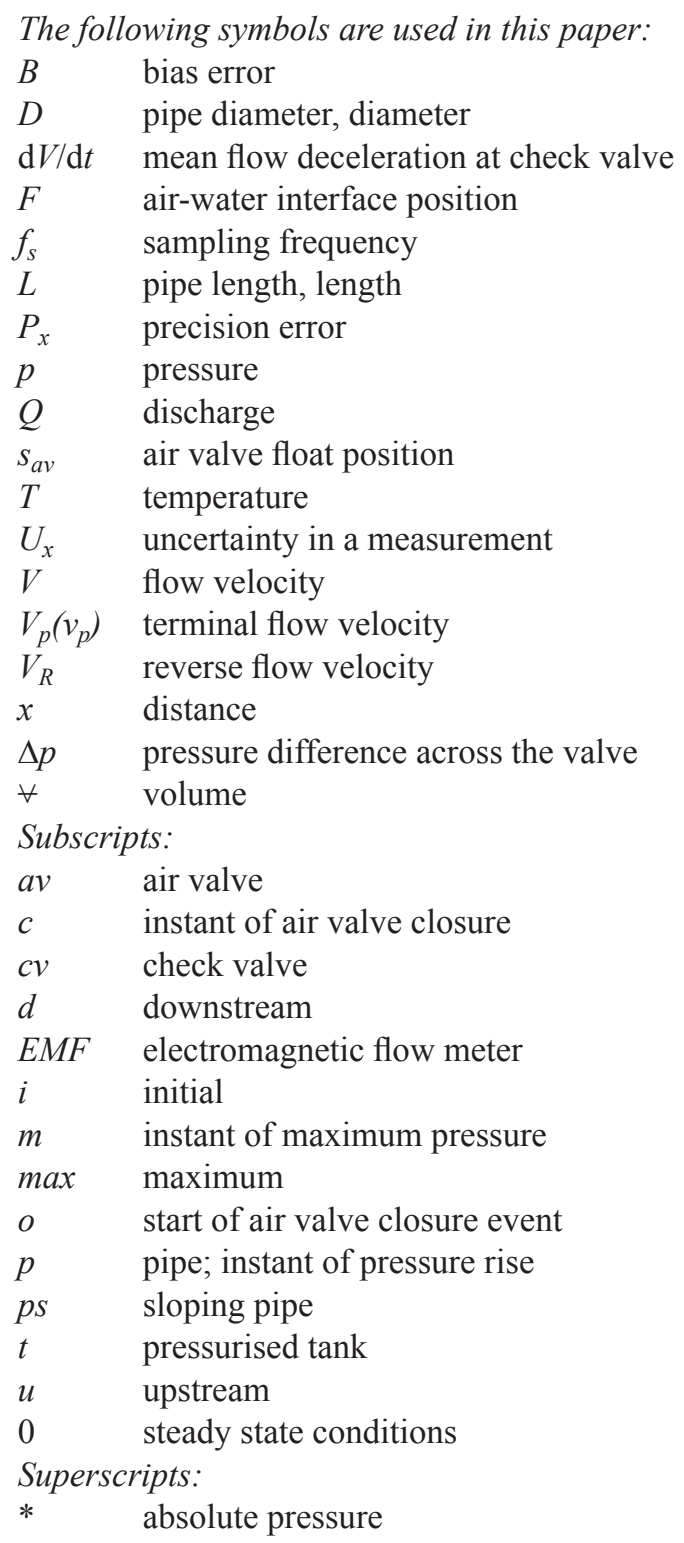

\section{REFERENCES}

[1] Thorley, A.R.D. (2004). Fluid transients in pipeline systems, 2nd ed. Professional Publishing Limited, London.

[2] Cabrera, E., Fuertes, V., García-Serra, J., Arregui, F., Gascón, L., Palau, C. (2003). Reviewing air valves selection. Pumps, Electromechanical Devices and Systems Applied to Urban Water Management, Cabrera, E., Cabrera, E.Jr. (eds.), vol. 2, A.A. Balkema Publishers, Lisse, p. 633-640. 
[3] Ramos, H., Borga, A., Bergant, A., Covas, D., Almeida, A.B. (2005). Analysis of surge effects in pipe systems by air release/venting. Portuguese Journal of Water Resources (Revista Recursos Hidricos), vol. 26, no. 2, p. 45-55.

[4] Campbell, A. (1983). The effect of air valves on surge in pipelines. Proceedings of the $4^{\text {th }}$ International Symposium on Pressure Surges, BHRA, p. 89-102.

[5] Lee, T.S. (1999). Air influence on hydraulic transients on fluid system with air valves. Journal of Fluids Engineering, vol. 121, no. 3, p. 646-650, DOI:10.1115/1.2823518.

[6] Kruisbrink, A., Arregui, F., Carlos, M., Bergant, A. (2004). Dynamic performance characterization of air valves. The Practical Application of Surge Analysis for Design and Operation, Murray, S.J. (ed.), vol. I, BHR Group Limited, Cranfield, p. 33-47.

[7] Lingireddy, S., Wood, D.J., Zlocower, N. (2004). Pressure surges in pipeline systems resulting from air releases. Journal of American Water Works Association, vol. 96, no. 7, p. 88-94.

[8] Fuertes, V.S., Iglesias, P.L., Lopez, P.A., Mora, D. (2009). Air valves sizing and hydraulic transients in pipes due to air release flow. Proceedings of the 33rd IAHR Congress: Water Engineering for a Sustainable Environment, CD-ROM, paper 10463.

[9] Bergant, A., Bournaski, E., Arregui, F., Kruisbrink, A. (2004). Column separation measurements in a largescale experimental apparatus. The Practical Application of Surge Analysis for Design and Operation, Murray, S.J. (ed.), vol. II, BHR Group Limited, Cranfield, p. 589-604.

[10] Wylie, E.B., Streeter, V.L. (1993). Fluid Transients in Systems. Prentice-Hall Inc., Englewood Cliffs.

[11] Bergant, A., Simpson, A.R., Tijsseling, A.S. (2006). Water hammer with column separation: a historical review. Journal of Fluids and Strucures, vol. 22, no. 2, p. 135-171, DOI:10.1016/j.jfluidstructs.2005.08.008.

[12] Bergant, A., Arregui, F., Cabrera, E., Bournaski, E., Kruisbrink, A., de Silva, A., Thorley, A.R.D. (2007). Dynamic behaviour of air valves. Transnational access to major research infrastructures - access to experimental facilities of WL|Delft Hydraulics. Report No. 1412, Litostroj E.I., Ljubljana.

[13] Lemos de Lucca, Y.F., Alcântara de Aquino, G., Dalfré Filho, J.G. (2010). Experimental apparatus to test air trap valves. Proceedings of the 25th IAHR Symposium on Hydraulic Machinery and Systems, Susan-Resiga, R., Muntean, S., Bernad, S.I. (eds.), vol. 2, p. 801-807.

[14] Gale, J., Bergant, A. (2010). Modeling of dynamic response of air valves during pipeline transients. Proceedings of the 1st European IAHR Congress, CDROM, Paper FMIIb.

[15] Graze, H.R., Horlacher, H.B. (1983). Pressure transients following the collapse of vapour cavities. Proceedings of the $6^{\text {th }}$ International Symposium on Hydraulic Transients in Power Stations, IAHR, Gloucester.

[16] Simpson, A.R., Bergant, A. (1994). Developments in pipeline column separation experimentation. Journal of Hydraulic Research, vol. 32, no. 2, p. 183-194, DOI:10.1080/00221689409498722.

[17] Kruisbrink, A. (1997). The dynamic behaviour of check valves. Ph.D. Thesis, City University of London, London.

[18] Kruisbrink, A.C.H., Lavooij, C.S.W., Koetzier, H. (1986). Dynamic behaviour of large non-return valves. Proceedings of the $5^{\text {th }}$ International Conference on Pressure Surges, BHRA, Hannover, p. 237-244.

[19] Kruisbrink, A.C.H., Thorley, A.R.D. (1994). Dynamic characteristics for damped check valves. Proceedings of the $2^{\text {nd }}$ International Conference on Water Pipeline Systems, BHR Group, Edinburgh, p. 459-476.

[20] Coleman, H.W., Steele, W.G. (1989). Experimentation and uncertainty analysis for engineers. John Wiley and Sons, New York.

[21] Riasi, A., Raisee, M., Nourbakhsh, A. (2010). Simulation of transient flow in hydroelectric power plants using unsteady friction. Strojniški vestnik Journal of Mechanical Engineering, vol. 56, no. 6, p. 377-384.

[22] Gale, J., Tiselj, I. (2008). Godunov's method for simulations of fluid-structure interaction in piping systems. Journal of Pressure Vessel Technology, vol. 130, no. 3, p. 031304-1 - 031304-12. 